\title{
Bilateral origin of a split circumflex coronary artery
}

\author{
Sharath Babu Nelagondanahalli Manjunath, ${ }^{1}$ Anoop George Alex, ${ }_{1}$ Lijo Varghese, ${ }^{2}$ \\ Oommen Kattunilam George ${ }^{1}$
}

${ }^{1}$ Cardiology, Christian Medical College and Hospital Vellore, Vellore, Tamil Nadu, India ${ }^{2}$ Christian Medical College Vellore Association, Vellore, Tamil Nadu, India

\section{Correspondence to}

Dr Sharath Babu Nelagondanahalli Manjunath; nmsbabu18@yahoo.com

Accepted 25 July 2020

\section{DESCRIPTION}

A 60-year-old man presented with exertional chest heaviness of 1 year duration. On evaluation, his ECG showed no significant abnormality to suggest previous ischaemia. He was subjected to coronary angiography. On selective coronary angiogram of the left coronary system, there was left main coronary artery bifurcating into a normal left anterior descending artery and a circumflex artery which showed minor disease. The circumflex artery continued as the second obtuse marginal branch after giving off to the first obtuse marginal artery. The distal circumflex artery could not be visualised associated with non-perfused myocardium (figures 1 and 2 and videos 1 and 2). This 'nonperfused myocardium' sign represents a myocardial region that is not supplied by any visualised vessel. ${ }^{1}$ Dominant right coronary artery was seen filling through left to right collaterals.

Selective right coronary system angiogram showed the right coronary artery giving off a second branch (after conus branch) that crossed over to the left side perfusing the distal circumflex territory and the native right coronary artery was occluded. The branch that crossed to the left side continued as distal circumflex artery after giving third obtuse marginal artery (figure 3 and video 3 ). Hence it was concluded that the circumflex artery had its origin from both the left and right coronary systems. The left coronary system gave rise to the proximal left circumflex artery and obtuse marginals, whereas the

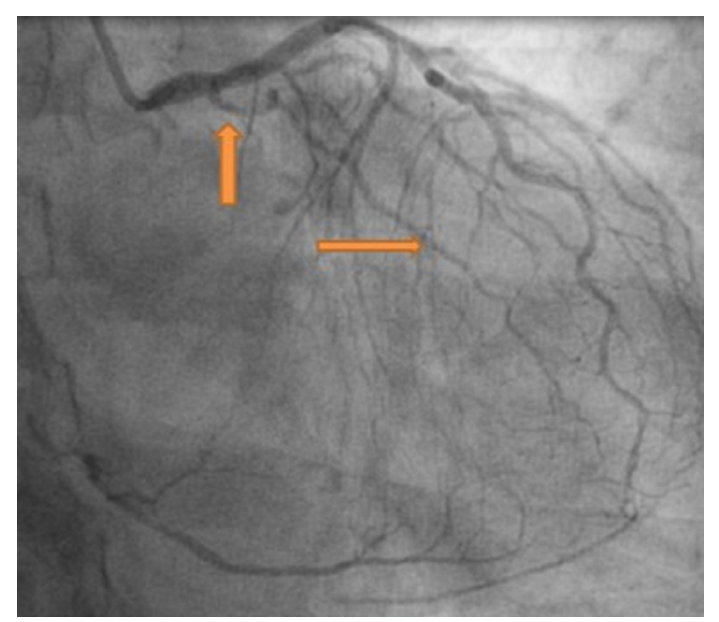

Figure 1 Selective angiogram of the left coronary system (right anterior oblique view with caudal angulation) showing circumflex artery (vertical arrow) continuing as second obtuse marginal artery (horizontal arrow). Distal circumflex artery not seen.

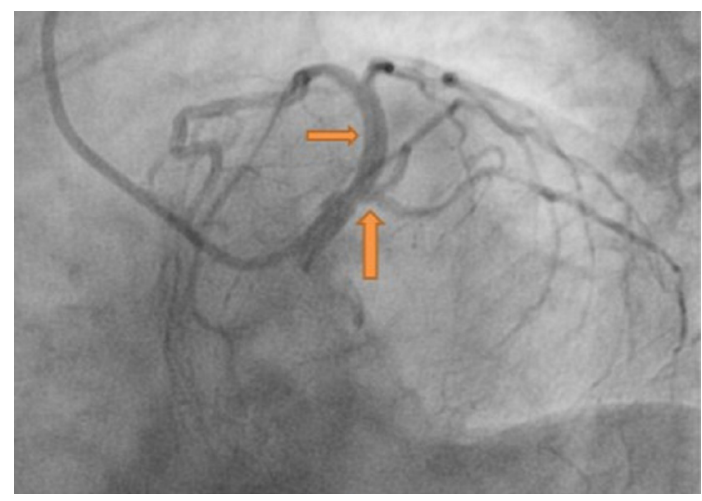

Figure 2 Selective angiogram of the left coronary system (left anterior oblique view) showing left main coronary artery dividing into the left anterior descending artery (horizontal arrow) and circumflex artery (vertical arrow) which continues as second obtuse marginal artery after giving off the first obtuse marginal artery.

right coronary system branched to distal circumflex and the third obtuse marginal artery.

This variety of anomalous circumflex artery has been rarely described in the literature and also termed as double circumflex arteries or twin circumflex arteries. ${ }^{2}$ Only a few case reports are

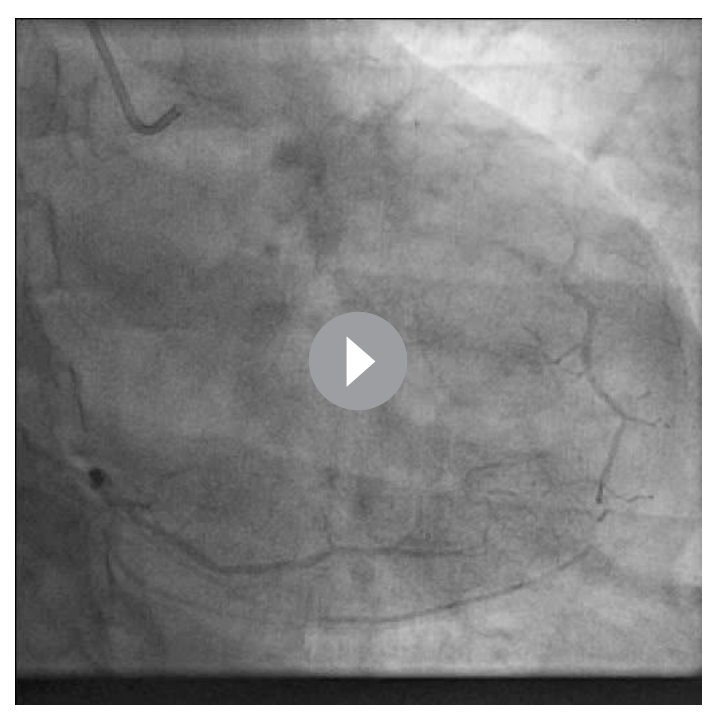

Video 1. Selective angiogram of left coronary system(right anterior oblique view with caudal angulation) showing circumflex artery continuing as second obtuse marginal artery. Distal circumflex artery not seen in posterior atrioventricular groove where coronary sinus is clearly noted. Also sign of nonperfused myocardium noted with contracting myocardium and absent coronary vessel in the territory of distal circumflex artery. 


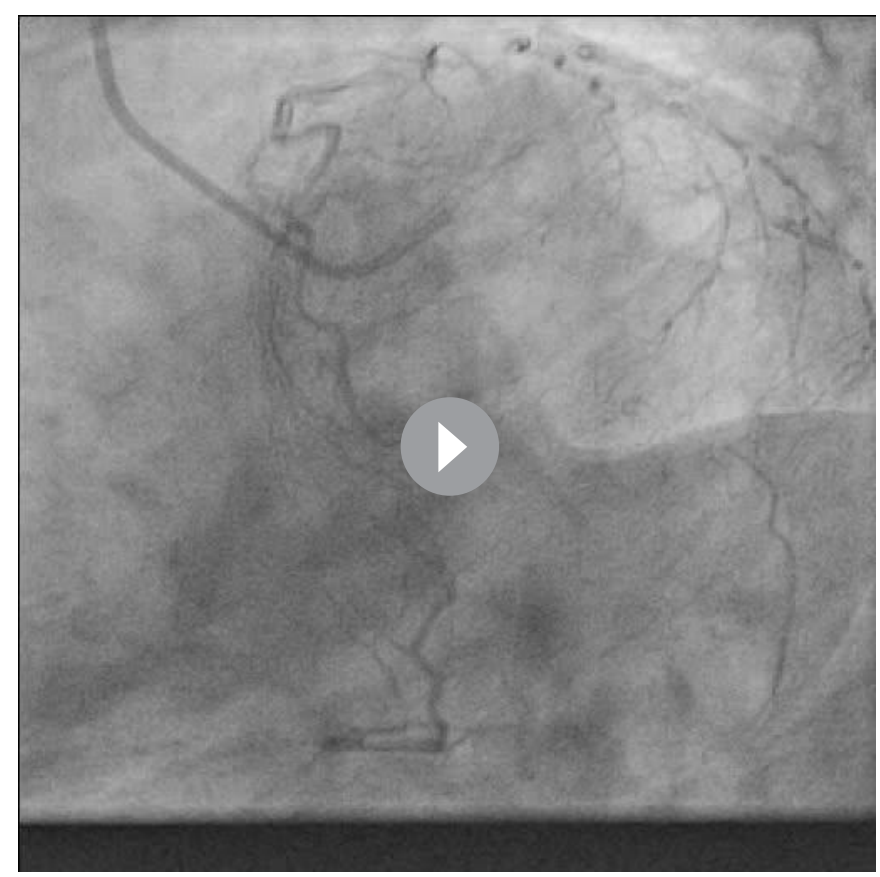

Video 2. Selective angiogram of left coronary system- (Left anterior oblique view) showing left main coronary artery dividing into left anterior descending artery and circumflex artery which continues as second obtuse marginal artery after giving off first obtuse marginal artery.

available of this type of anomaly. This coronary anomaly usually has a retroaortic course and has been described as clinically benign. This variant is not haemodynamically significant, but may complicate valve surgery. ${ }^{13}$ The significance of the anomaly lies in patients undergoing percutaneous coronary intervention

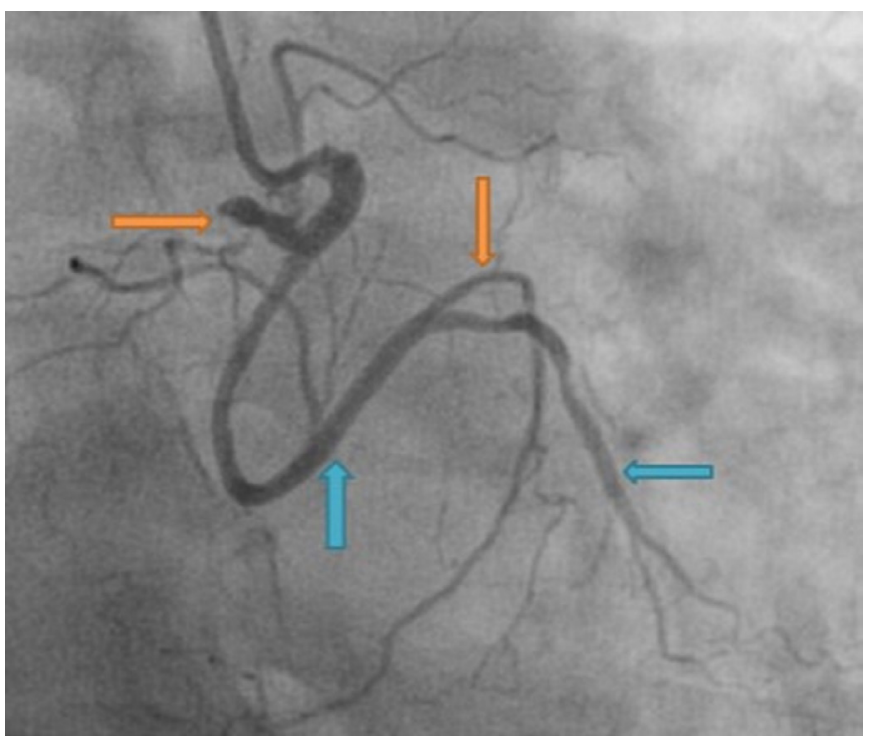

Figure 3 Selective angiogram of the right coronary system (right anterior oblique view) showing the vessel originating from the right coronary artery that crosses to the left side (blue vertical arrow). this vessel continues as distal circumflex artery (yellow vertical arrow) giving off the third obtuse marginal artery (blue horizontal arrow). Occluded right coronary artery noted (yellow horizontal arrow).

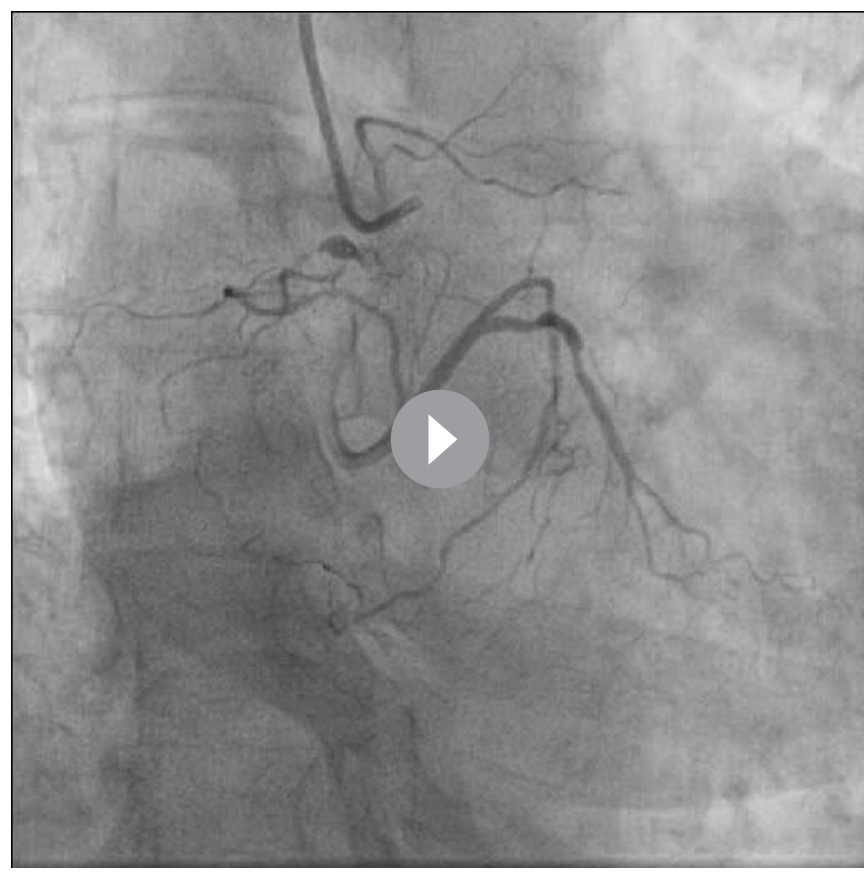

video 3. Selective angiogram of right coronary system- (right anterior oblique view with caudal angulation) showing the circumflex artery originating from right coronary artery. The circumflex artery crosses to left side and continues as distal circumflex artery giving off third obtuse marginal artery. Occluded right coronary artery noted.

\section{Learning points}

- 'Sign of non-perfused myocardium' is an important clue to look for anomalous coronary arteries.

- Anomalous circumflex artery from the right coronary artery (usually retroaortic) might run through intramural or interarterial course during the crossing to the left side which needs confirmation through radiological imaging or aortic root angiogram.

- Coronary artery disease affecting this anomalous circumflex artery might cause difficulty in percutaneous interventions and cardiac surgery.

or cardiac surgery where it might be difficulty and risk of vessel injury. ${ }^{4}$ If the anomalous circumflex originates from the right coronary sinus or very proximal right coronary artery, there might be a possibility of missing the artery unless the catheter is properly engaged during angiography. In our case, anomalous circumflex artery originated from the native right coronary artery and it was free of disease. The right coronary artery of our patient was recanalised (percutaneous coronary angioplasty) without difficulty.

Contributors SBNM involved in conception and design, acquisition of data or analysis and interpretation of data. AGA involved in reporting. LV contributed in conception and design. OKG performed analysis.

Funding The authors have not declared a specific grant for this research from any funding agency in the public, commercial or not-for-profit sectors.

Competing interests None declared.

Patient consent for publication Obtained.

Provenance and peer review Not commissioned; externally peer reviewed. 


\section{REFERENCES}

1 Ali M, Hanley A, McFadden EP, et al. Coronary artery anomalies: a practical approach to diagnosis and management. Heart Asia 2011;3:8-12.

2 Coşansu K, Tarık Ağaç M, Kılıç H, et al. Twin circumflex arteries: a rare coronary artery anomaly. J Tehran Heart Cent 2018;13:32-4.
3 Villa AD, Sammut E, Nair A, et al. Coronary artery anomalies overview: the normal and the abnormal. World J Radiol 2016;8:537-55.

4 Hendiri T, Alibegovic J, Bonvini RF, et al. Successful angioplasty of an occluded aberrant coronary artery: a rare cause of acute myocardial infarction. Acute Card Care 2006:8:125-7.

Copyright 2020 BMJ Publishing Group. All rights reserved. For permission to reuse any of this content visit https://www.bmj.com/company/products-services/rights-and-licensing/permissions/

BMJ Case Report Fellows may re-use this article for personal use and teaching without any further permission.

Become a Fellow of BMJ Case Reports today and you can:

- Submit as many cases as you like

- Enjoy fast sympathetic peer review and rapid publication of accepted articles

- Access all the published articles

- Re-use any of the published material for personal use and teaching without further permission

Customer Service

If you have any further queries about your subscription, please contact our customer services team on +44 (0) 2071111105 or via email at support@bmj.com.

Visit casereports.bmj.com for more articles like this and to become a Fellow 